\title{
WITHIN- AND BETWEEN-SESSION RELIABILITY OF A PEDAL FORCE SYSTEM FOR POWER OUTPUT AND PEDAL FORCE EFFECTIVENESS MEASUREMENTS
}

original paper

( ) University School of Physical Education in Wroclaw

DOI: https://doi.org/10.5114/hm.2020.94197

\section{RODRIGO BINI ${ }^{1,2}$, PATRIA HUME ${ }^{2}$}

${ }^{1}$ La Trobe Rural Health School, La Trobe University, Bendigo, Australia

${ }^{2}$ Sports Performance Research Institute New Zealand, Auckland University of Technology, Auckland, New Zealand

\begin{abstract}
Purpose. The study assessed within- and between-session reliability of power output (PO) and pedal force effectiveness and compared PO from the pedals with the Lode Excalibur cycle ergometer.

Methods. Seventeen male cyclists performed 10 trials at 3 levels of PO (1.5, 2.5, and $3.5 \mathrm{~W} / \mathrm{kg})$ and 3 cadences (60, 80, and $100 \mathrm{rpm}$ ) in 2 sessions. Instrumented pedals and a portable motion tracking system were synchronized to collect pedal forces and 3D full body motion, respectively. PO and the index of effectiveness (IE) were compared within and between sessions for the pedals while PO was compared with the Lode Excalibur.

Results. Good agreement was observed for PO within sessions whilst right and left pedal IEs were moderate. Betweensession reliability ranged from poor to good for PO measured from the pedals, and reliability for IE ranged from poor to good. Significant differences in PO were observed between the pedals and the Lode Excalibur ergometer (17-50 W).

Conclusions. The customized system to measure pedal forces was reliable within a given session for measuring IE and PO but variability in data increased in the second session, potentially because of the repositioning of the motion tracking sensors. Validity in measuring PO from the pedals without the use of the crank encoder is questionable.
\end{abstract}

Key words: force effectiveness, Xsens, motion tracking, cycling

\section{Introduction}

Performance in endurance cycling and triathlon has been evaluated by using power output because of the strong reliability of this measure [1,2]. Power meters have been designed to measure power output at crank sets, crank arms, or wheel hubs. More recently, power output has been measured by instrumented pedals that enable per-leg assessment of power production, which provides information on asymmetries in power output during cycling. Although instrumented pedals have been used in biomechanics laboratories for many years [3-6], their availability as commercial products is more recent. These commercial systems have shown to be accurate in comparison with the SRM power meter, often used as a gold standard [7-12].

A limitation of most pedal-based power meters is that they only provide data on power output, which therefore does not allow adequate assessment of ped- alling technique. Traditionally, pedalling technique has been evaluated by the ability of cyclists to transfer force from the pedals in a way that helps to rotate the pedals in favour of the crank movement. The most often used measure to translate this ability for cyclists is the index of effectiveness (IE), defined as the ratio between the impulse from the effective force (i.e. force perpendicular to the crank) and the impulse from the total force applied to the pedals [13-16]. Better technique (i.e. larger transfer of force to the cranks) has been associated with larger IE values (which range from 0 to 100\%). Using a different approach, commercial power meters (i.e. Garmin Vector, Favero Assioma, Inpeak Powercrank) enable the assessment of technique via torque effectiveness, which is calculated as a difference between positive and negative torques (i.e. evenness of torques) [14].

More recently, commercial pedals have provided measurements of force throughout the crank cycle, which allows improved assessment of pedalling tech-

Correspondence address: Rodrigo Bini, La Trobe Rural Health School, La Trobe University, Flora Hill Campus,

Postcode: 3550, e-mail: r.bini@latrobe.edu.au

Received: April 30, 2019

Accepted for publication: January 24, 2020

Citation: Bini R, Hume P. Within- and between-session reliability of a pedal force system for power output and pedal force effectiveness measurements. Hum Mov. 2020;21(4):69-78; doi: https://doi.org/10.5114/hm.2020.94197. 
nique. The benefit in measuring force is that it enables the assessment of true effectiveness, in comparison with torque effectiveness, because peak torque and peak pedal forces are not often time-aligned during the crank cycle [17]. Among the options on the market, the I-Crank system (Sensix, France) also enables synchronization of pedal force with motion capture systems, which allows the extraction of additional measures from the movement (e.g. joint torques). However, one limitation of this system is that it does not provide a crank angular sensor that would fit into most cycle ergometers. As an example, the Lode Excalibur $[7,18]$ and the Wattbike ergometers [19] have been used in many exercise physiology studies but are incompatible with the crank sensor provided by Sensix. Therefore, movement data must be gathered by motion analysis systems, which potentially reduces the reliability of measures taken from these pedals because of different sample rates from multiple sensors. This method requires large accuracy in data acquisition and handling to ensure that both data sets (i.e. force and motion) are optimally time-aligned, particularly when calculations of joint torques are required.

In order to employ a system that would allow measurements of performance (i.e. power output and technique) and clinical related measures from cyclists (i.e. joint forces) during intervention studies (i.e. measurements across multiple sessions), this study assessed the within- and between-session reliability of power output and pedalling technique (from IE measures). A comparison with power output from the Lode Excalibur allowed to explore the potential accuracy from this customized system in comparison with prior evidence on the accuracy of the I-Crank system in measuring crank torque [20].

\section{Material and methods}

\section{Study design}

The study used a cross-sectional randomized comparative design. The participants attended 2 laboratory sessions which involved cycling at 3 predetermined power outputs and cadences, in random order. Data from the instrumented pedals were collected simultaneously with motion data and with power output from the cycle ergometer.

\section{Participants}

A total of 17 male cyclists, ranging from recreational (3) to national competitive (14), without musculoskele- tal or neurological diseases participated in the study. At the time of the study, they were characterized by $24 \pm 5.9$ years of age, $75 \pm 8 \mathrm{~kg}$ of body mass, $181 \pm$ $6 \mathrm{~cm}$ of stature, and $6 \pm 2.1$ years of racing experience. The cyclists were provided with full information on the study.

\section{Protocol}

The cyclists' bicycles were measured in the first session (i.e. saddle height, bar drop, fore-back saddle position, and handlebar reach) and replicated in the cycle ergometer (Excalibur Sport, Lode, Netherlands). In order to enable motion-related measurements, anthropometric data were collected from each cyclist, in accordance with guidelines from the motion tracking system manufacturer (Xsens, Netherlands). Stature, arm span, foot length, ankle height, knee height, hip width, and shoulder width were measured on the right side of the body of each cyclist. Overall, 15 wireless sensors (MVN Awinda; Xsens, Netherlands) were attached to predefined body segments, as described by the manufacturer, prior to a static pose calibration.

The cyclists were positioned on the cycle ergometer and warmed up for $10 \mathrm{~min}$ at $100 \mathrm{~W}$ at a self-selected pedalling cadence. During the warm-up, they were familiarized with the visual feedback of their pedalling cadence so they could control it at $\pm 2 \mathrm{rpm}$ during all trials. The cyclists performed 1 trial of 1 -min cycling at 9 randomized combinations of power outputs (1.5, 2.5 , and $3.5 \mathrm{~W} / \mathrm{kg}$ ) and pedalling cadences $(60,80$, and $100 \mathrm{rpm})$. With a prior study using approximately $2.4 \mathrm{~W} / \mathrm{kg}$ [21], we expanded the power output to a lower intensity $(1.5 \mathrm{~W} / \mathrm{kg})$ and a higher intensity $(3.5 \mathrm{~W} / \mathrm{kg})$. The cycle ergometer was manually configured in the constant wattage mode which allowed for wheel resistance to be constantly modulated once pedalling cadence was changed in order to sustain a fixed power output. The first trial was repeated at the end of the session to assess within-session variability of outcomes. After 2-7 days, the cyclists returned to the laboratory to perform the same protocol in a new random order in an attempt to keep learning effects between sessions minimized. The participants were allowed to use their own shoes and cleats (i.e. Shimano) during all trials in both sessions.

\section{Data collection}

A pair of instrumented pedals were attached to the cycle ergometer (I-Crankset system, Sensix, France) and controlled by the manufacturer software to col- 


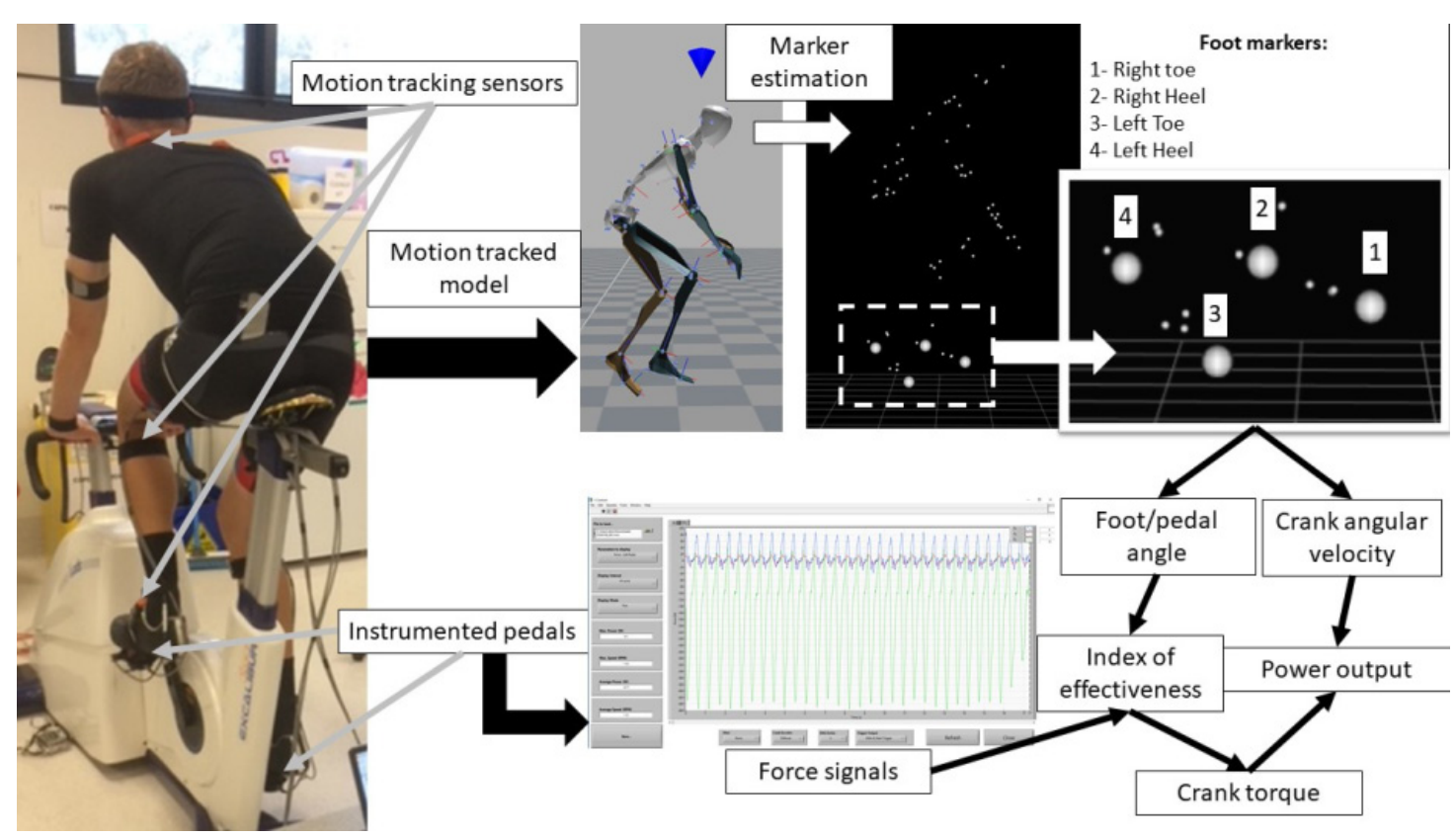

Figure 1. Diagram illustrating the customized system to measure power output and index of effectiveness. Arrows and insets show the sequence of the data for calculations of the intended outcomes

lect 3D pedal force data at $300 \mathrm{~Hz}$. In parallel, the motion tracking system collected data at $60 \mathrm{~Hz}$ using the manufacturer software (MVN Studio v.4.4, Xsens, Netherlands). The Xsens system has been shown accurate in measuring joint angles for a range of activities [22-24], with a standard error of measurement smaller than $5^{\circ}$ when compared with an optoelectronic system [23]. Both systems were off-line synchronized by using a TTL trigger signal sent from the motion tracking system to the instrumented pedals software and data were collected during the last $20 \mathrm{~s}$ of each trial.

\section{Data analysis}

Data were exported from the pedal force and motion tracking systems and imported into customized software in MATLAB (R2018b, MathWorks, USA) for further analysis. Pedal forces and 3D motion were smoothed by using a second-order zero lag low pass Butterworth filter with cut-off frequencies of $10 \mathrm{~Hz}$ and $6 \mathrm{~Hz}$, respectively. The motion tracking system predicted bony landmarks from the segmentation used to derive the biomechanical model. For the analysis of pedal motion (in order to calculate forces transferred to the cranks), the predicted foot and heel centres were applied to determine the angular inclination of the footpedal in relation to the global coordinate system. The predicted foot centre was also used to estimate the top of the crank cycle because of the clip-in system utilised by all cyclists, similar to methods applied in prior studies [25, 26]. The shoe-pedal offset from the cleat attachment was measured with a goniometer and corrected for calculations of foot-pedal angle (i.e. $5^{\circ}$ ). This allowed the selection of 10 consecutive crank cycles for the analysis of IE (as described by LaFortune and Cavanagh [16]) and power output. Once crank torque was calculated (using pedal transfer force via footpedal angle measurements), angular velocity was determined from the 10 cycles from average pedalling cadence, which enabled calculations of mean power output for each full crank cycle. Mean IE and power output from the 10 crank cycles were then converted into a mean value per trial for each cyclist. The sequence from data extraction to processing is illustrated in Figure 1.

\section{Statistical analysis}

Intra-class correlation coefficients (ICC) were used to assess the reliability of the data between sessions, for the pedal force system (i.e. IE and power output), and within sessions, for the pedal force system and the cycle ergometer (power output only, manually registered from the ergometer head unit). For comparisons between systems (pedals vs. cycle ergometer), data from both sessions were collated for each combination of power output and pedalling cadence. Typical errors were calculated for all comparisons (within and between sessions and between systems) as the ratio between the standard deviation of the differences and 


\section{HUMAN MOVEMENT}

R. Bini, P. Hume, Reliability of a pedal force system

the square root of 2 [27]. Student's $t$-tests were employed to assess differences within and between sessions (pedals only) and in relation to the cycle ergometer (power output only) along with Cohen's effect sizes $(d)$. ICCs were ranked as poor (0-0.5), moderate (0.5-0.75), good (0.75-0.90), and excellent $(>0.9)$ [28], whilst Cohen's $d$ was ranked as trivial (0-0.25), small (0.25-0.5), moderate (0.5-0.80), and large $(>0.80)$ [29].

\section{Ethical approval}

The research related to human use has complied with all the relevant national regulations and institutional policies, has followed the tenets of the Declaration of Helsinki, and has been approved by the ethics committee from La Trobe University (HEC17-085).

\section{Informed consent}

Informed consent has been obtained from all individuals included in this study.

\section{Results}

Within-session reliability

Good agreement was observed for power output within sessions whilst right and left pedal IE values were moderate. Differences were trivial and non-significant for power output and for IE (Table 1).

\section{Between-session reliability}

Between-session reliability ranged from poor to good for power output measured from the pedals. Differences ranged from trivial to moderate and were not significant between sessions. Reliability for IE ranged from poor to good, with differences being trivial to large. The trial at $3.5 \mathrm{~W} / \mathrm{kg}-60 \mathrm{rpm}$ resulted in significant differences between sessions for the right pedal (Table 2).

Table 1. Within-session reliability of power output and index of effectiveness measured by instrumented pedals. Typical errors (TE) and intra-class correlation coefficients (ICC) are presented for comparisons between trials

\begin{tabular}{lccc} 
& Power output & Right index of effectiveness & Left index of effectiveness \\
\cline { 2 - 4 } First trial & $198 \pm 72 \mathrm{~W}$ & $54 \pm 8 \%$ & $56 \pm 6 \%$ \\
Last trial & $201 \pm 65 \mathrm{~W}$ & $54 \pm 6 \%$ & $56 \pm 5 \%$ \\
Difference & $2 \pm 23 \mathrm{~W}(3 \pm 14 \%)$ & $1 \pm 4 \%$ & $<1 \pm 4 \%$ \\
$\mathrm{p}$ & 0.61 & 0.26 & 0.73 \\
Cohen's $d$ & 0.04 (trivial) & 0.12 (trivial) & 0.05 (trivial) \\
TE & 16 W (10\%) & $2 \%$ & $3 \%$ \\
ICC & 0.94 (good) & 0.88 (moderate) & 0.78 (moderate) \\
\hline
\end{tabular}

Table 2. Between-session reliability of power output and index of effectiveness measured by instrumented pedals for different combinations of power outputs $(1.5,2.5$, and $3.5 \mathrm{~W} / \mathrm{kg})$ and pedalling cadences $(60,80$, and 100 rpm). Typical errors (TE) and intra-class correlation coefficients (ICC) are presented for comparisons between sessions

\begin{tabular}{|c|c|c|c|}
\hline & \multirow{2}{*}{\multicolumn{2}{|c|}{ Right index of effectiveness }} & \multirow[b]{2}{*}{ Left index of effectiveness } \\
\hline & & & \\
\hline \multicolumn{4}{|c|}{$1.5 \mathrm{~W} / \mathrm{kg}-60 \mathrm{rpm}$} \\
\hline Session 1 & $107 \pm 18 \mathrm{~W}$ & $51 \pm 5 \%$ & $53 \pm 4 \%$ \\
\hline Session 2 & $113 \pm 19 \mathrm{~W}$ & $51 \pm 4 \%$ & $53 \pm 3 \%$ \\
\hline Difference & $<1 \pm 10 \mathrm{~W}(<1 \pm 9 \%)$ & $3 \pm 1 \%$ & $2 \pm 2 \%$ \\
\hline $\mathrm{p}$ & 0.48 & 0.42 & 0.89 \\
\hline Cohen's $d$ & 0.33 (small) & 0.35 (small) & 0.06 (trivial) \\
\hline $\mathrm{TE}$ & $4 \mathrm{~W}(4 \%)$ & $1 \%$ & $1 \%$ \\
\hline ICC & 0.94 (good) & 0.98 (good) & 0.90 (good) \\
\hline \multicolumn{4}{|c|}{$2.5 \mathrm{~W} / \mathrm{kg}-60 \mathrm{rpm}$} \\
\hline Session 1 & $165 \pm 30 \mathrm{~W}$ & $54 \pm 7 \%$ & $58 \pm 8 \%$ \\
\hline Session 2 & $165 \pm 12 \mathrm{~W}$ & $58 \pm 5 \%$ & $59 \pm 4 \%$ \\
\hline Difference & $16 \pm 8 W(9 \pm 4 \%)$ & $5 \pm 5 \%$ & $6 \pm 6 \%$ \\
\hline $\mathrm{p}$ & 0.93 & 0.23 & 0.63 \\
\hline Cohen's $d$ & 0.04 (trivial) & 0.60 (moderate) & 0.22 (trivial) \\
\hline $\mathrm{TE}$ & $20 \mathrm{~W}(14 \%)$ & $3 \%$ & $5 \%$ \\
\hline ICC & 0.41 (poor) & 0.71 (moderate) & 0.48 (poor) \\
\hline
\end{tabular}




\begin{tabular}{|c|c|c|c|}
\hline \multicolumn{4}{|c|}{$3.5 \mathrm{~W} / \mathrm{kg}-60 \mathrm{rpm}$} \\
\hline Session 1 & $232 \pm 50$ & $58 \pm 5 \%$ & $62 \pm 6 \%$ \\
\hline Session 2 & $258 \pm 65$ & $65 \pm 6 \%$ & $66 \pm 5 \%$ \\
\hline Difference & $31 \pm 55 \mathrm{~W}(17 \pm 29 \%)$ & $7 \pm 8 \%$ & $5 \pm 6 \%$ \\
\hline $\mathrm{p}$ & 0.37 & $0.02 *$ & 0.26 \\
\hline Cohen's $d$ & 0.46 (small) & 1.31 (large) & 0.54 (moderate) \\
\hline $\mathrm{TE}$ & 39 W (20\%) & $6 \%$ & $4 \%$ \\
\hline ICC & 0.50 (moderate) & 0.09 (poor) & 0.52 (moderate) \\
\hline \multicolumn{4}{|c|}{$1.5 \mathrm{~W} / \mathrm{kg}-80 \mathrm{rpm}$} \\
\hline Session 1 & $127 \pm 22 \mathrm{~W}$ & $47 \pm 5 \%$ & $51 \pm 3 \%$ \\
\hline Session 2 & $128 \pm 9 \mathrm{~W}$ & $51 \pm 5 \%$ & $52 \pm 3 \%$ \\
\hline Difference & $7 \pm 10 W(6 \pm 8 \%)$ & $4 \pm 4 \%$ & $2 \pm 4 \%$ \\
\hline $\mathrm{p}$ & 0.89 & 0.06 & 0.46 \\
\hline Cohen's $d$ & 0.06 (trivial) & 0.83 (large) & 0.32 (small) \\
\hline $\mathrm{TE}$ & $7 \mathrm{~W}(6 \%)$ & $3 \%$ & $3 \%$ \\
\hline ICC & 0.87 (good) & 0.72 (moderate) & 0.34 (poor) \\
\hline \multicolumn{4}{|c|}{$2.5 \mathrm{~W} / \mathrm{kg}-80 \mathrm{rpm}$} \\
\hline Session 1 & $187 \pm 33 \mathrm{~W}$ & $51 \pm 6 \%$ & $56 \pm 4 \%$ \\
\hline Session 2 & $199 \pm 32 \mathrm{~W}$ & $54 \pm 5 \%$ & $56 \pm 4 \%$ \\
\hline Difference & $15 \pm 22 \mathrm{~W}(8 \pm 13 \%)$ & $3 \pm 4 \%$ & $2 \pm 2 \%$ \\
\hline $\mathrm{p}$ & 0.44 & 0.23 & 0.73 \\
\hline Cohen's $d$ & 0.35 (small) & 0.55 (moderate) & 0.15 (trivial) \\
\hline $\mathrm{TE}$ & $16 \mathrm{~W}(9 \%)$ & $3 \%$ & $2 \%$ \\
\hline ICC & 0.75 (moderate) & 0.66 (moderate) & 0.86 (good) \\
\hline \multicolumn{4}{|c|}{$3.5 \mathrm{~W} / \mathrm{kg}-80 \mathrm{rpm}$} \\
\hline Session 1 & $238 \pm 41 \mathrm{~W}$ & $55 \pm 4 \%$ & $59 \pm 4 \%$ \\
\hline Session 2 & $256 \pm 20 \mathrm{~W}$ & $58 \pm 4 \%$ & $60 \pm 2 \%$ \\
\hline Difference & $34 \pm 49 \mathrm{~W}(16 \pm 25 \%)$ & $4 \pm 5 \%$ & $3 \pm 4 \%$ \\
\hline $\mathrm{p}$ & 0.22 & 0.13 & 0.46 \\
\hline Cohen's $d$ & 0.60 (moderate) & 0.82 (large) & 0.36 (small) \\
\hline $\mathrm{TE}$ & $35 \mathrm{~W}(18 \%)$ & $3 \%$ & $3 \%$ \\
\hline ICC & 0.05 (poor) & 0.31 (poor) & 0.54 (moderate) \\
\hline \multicolumn{4}{|c|}{$1.5 \mathrm{~W} / \mathrm{kg}-100 \mathrm{rpm}$} \\
\hline Session 1 & $162 \pm 31 \mathrm{~W}$ & $47 \pm 5 \%$ & $51 \pm 3 \%$ \\
\hline Session 2 & $170 \pm 43 \mathrm{~W}$ & $49 \pm 5 \%$ & $52 \pm 5 \%$ \\
\hline Difference & $3 \pm 41 \mathrm{~W}(<1 \pm 25 \%)$ & $2 \pm 4 \%$ & $2 \pm 5 \%$ \\
\hline $\mathrm{p}$ & 0.73 & 0.35 & 0.72 \\
\hline Cohen's $d$ & 0.22 (trivial) & 0.42 (small) & 0.17 (trivial) \\
\hline $\mathrm{TE}$ & 29 W (18\%) & $3 \%$ & $4 \%$ \\
\hline ICC & 0.34 (poor) & 0.67 (moderate) & 0.20 (poor) \\
\hline \multicolumn{4}{|c|}{$2.5 \mathrm{~W} / \mathrm{kg}-100 \mathrm{rpm}$} \\
\hline Session 1 & $217 \pm 38 \mathrm{~W}$ & $51 \pm 6 \%$ & $55 \pm 4 \%$ \\
\hline Session 2 & $231 \pm 27 \mathrm{~W}$ & $54 \pm 5 \%$ & $57 \pm 4 \%$ \\
\hline Difference & $25 \pm 57 \mathrm{~W}(13 \pm 29 \%)$ & $3 \pm 5 \%$ & $3 \pm 6 \%$ \\
\hline $\mathrm{p}$ & 0.41 & 0.35 & 0.48 \\
\hline Cohen's $d$ & 0.43 (moderate) & 0.53 (moderate) & 0.40 (small) \\
\hline TE & $41 \mathrm{~W}(20 \%)$ & $4 \%$ & $4 \%$ \\
\hline ICC & 0.76 (good) & 0.55 (moderate) & 0.11 (poor) \\
\hline \multicolumn{4}{|c|}{$3.5 \mathrm{~W} / \mathrm{kg}-100 \mathrm{rpm}$} \\
\hline Session 1 & $259 \pm 47 \mathrm{~W}$ & $53 \pm 6 \%$ & $57 \pm 6 \%$ \\
\hline Session 2 & $281 \pm 22 \mathrm{~W}$ & $55 \pm 4 \%$ & $59 \pm 3 \%$ \\
\hline Difference & $31 \pm 51 \mathrm{~W}(13 \pm 21 \%)$ & $1 \pm 3 \%$ & $3 \pm 5 \%$ \\
\hline $\mathrm{p}$ & 0.17 & 0.49 & 0.36 \\
\hline Cohen's $d$ & 0.66 (moderate) & 0.34 (small) & 0.43 (small) \\
\hline $\mathrm{TE}$ & $36 \mathrm{~W}(15 \%)$ & $2 \%$ & $3 \%$ \\
\hline ICC & 0.23 (poor) & 0.83 (good) & 0.60 (moderate) \\
\hline
\end{tabular}

* significant difference between sessions 


\section{HUMAN MOVEMENT}

R. Bini, P. Hume, Reliability of a pedal force system

Table 3. Comparison for power output measured by the instrumented and the Lode Excalibur cycle ergometer for different combinations of power outputs (1.5, 2.5, and $3.5 \mathrm{~W} / \mathrm{kg}$ ) and pedalling cadences (60, 80, and 100 rpm). Typical errors (TE) and intra-class correlation coefficients (ICC) are presented for comparisons between pedals and Lode

\begin{tabular}{lcc}
\cline { 2 - 2 } & Pedals & Lode \\
\hline $1.5 \mathrm{~W} / \mathrm{kg}-60 \mathrm{rpm}$ & $110 \pm 18 \mathrm{~W} \quad 111 \pm 10 \mathrm{~W}$ \\
Power output & $1 \pm 11 \mathrm{~W}(2 \pm 9 \%)$ \\
Difference & 0.54 \\
$\mathrm{p}$ & 0.10 (trivial) \\
Cohen's $d$ & $7 \mathrm{~W}(6 \%)$ \\
$\mathrm{TE}$ & 0.75 (moderate) \\
$\mathrm{ICC}$ &
\end{tabular}

\begin{tabular}{lc}
\hline $2.5 \mathrm{~W} / \mathrm{kg}-60 \mathrm{rpm}$ & \\
Power output & $165 \pm 21 \mathrm{~W} \quad 182 \pm 13 \mathrm{~W}$ \\
Difference & $17 \pm 16 \mathrm{~W}(10 \pm 9 \%)$ \\
$\mathrm{p}$ & $0.02^{*}$ \\
Cohen's $d$ & 0.96 (large) \\
$\mathrm{TE}$ & $11 \mathrm{~W}(6 \%)$ \\
$\mathrm{ICC}$ & 0.61 (moderate) \\
\hline
\end{tabular}

\begin{tabular}{lc}
\hline $3.5 \mathrm{~W} / \mathrm{kg}-60 \mathrm{rpm}$ & \\
Power output & $245 \pm 58 \mathrm{~W} 264 \pm 38 \mathrm{~W}$ \\
Difference & $19 \pm 34 \mathrm{~W}(8 \pm 12 \%)$ \\
$\mathrm{p}$ & 0.26 \\
Cohen's $d$ & 0.42 (moderate) \\
$\mathrm{TE}$ & $24 \mathrm{~W}(9 \%)$ \\
$\mathrm{ICC}$ & 0.72 (moderate) \\
\hline
\end{tabular}

\begin{tabular}{lc}
\hline $1.5 \mathrm{~W} / \mathrm{kg}-80 \mathrm{rpm}$ & \\
Power output & $127 \pm 15 \mathrm{~W} \quad 109 \pm 10 \mathrm{~W}$ \\
Difference & $18 \pm 14 \mathrm{~W}(17 \pm 14 \%)$ \\
$\mathrm{p}$ & $0.01^{*}$ \\
Cohen's $d$ & 1.20 (large) \\
TE & $10 \mathrm{~W}(10 \%)$ \\
ICC & 0.48 (poor) \\
\hline
\end{tabular}

\begin{tabular}{lc}
\hline $2.5 \mathrm{~W} / \mathrm{kg}-80 \mathrm{rpm}$ & \\
Power output & $193 \pm 32 \mathrm{~W} \quad 185 \pm 18 \mathrm{~W}$ \\
Difference & $8 \pm 24 \mathrm{~W}(4 \pm 14 \%)$ \\
$\mathrm{p}$ & 0.46 \\
Cohen's $d$ & 0.30 (small) \\
$\mathrm{TE}$ & $18 \mathrm{~W}(10 \%)$ \\
$\mathrm{ICC}$ & 0.54 (moderate) \\
\hline
\end{tabular}

\section{Cycle ergometer comparison}

Agreement in power output measures between the pedals and the cycle ergometer ranged from poor to moderate (Table 2). Differences between systems ranged from trivial to large. Trials at $2.5 \mathrm{~W} / \mathrm{kg}-60 \mathrm{rpm}$, $1.5 \mathrm{~W} / \mathrm{kg}-80 \mathrm{rpm}, 1.5 \mathrm{~W} / \mathrm{kg}-100 \mathrm{rpm}$, and $2.5 \mathrm{~W} / \mathrm{kg}$ - 100 rpm presented significant differences between systems (Table 3).

\begin{tabular}{|c|c|c|}
\hline & \multirow{2}{*}{\multicolumn{2}{|c|}{ Lode }} \\
\hline & & \\
\hline \multicolumn{3}{|c|}{$3.5 \mathrm{~W} / \mathrm{kg}-80 \mathrm{rpm}$} \\
\hline Power output & $247 \pm 30 \mathrm{~W}$ & $255 \pm 13 \mathrm{~W}$ \\
\hline Difference & \multicolumn{2}{|c|}{$9 \pm 27 \mathrm{~W}(3 \pm 10 \%)$} \\
\hline $\mathrm{p}$ & \multicolumn{2}{|c|}{0.52} \\
\hline Cohen's $d$ & \multicolumn{2}{|c|}{0.29 (small) } \\
\hline $\mathrm{TE}$ & \multicolumn{2}{|c|}{$19 \mathrm{~W}(7 \%)$} \\
\hline ICC & \multicolumn{2}{|c|}{0.39 (poor) } \\
\hline
\end{tabular}

\begin{tabular}{lc}
\hline $1.5 \mathrm{~W} / \mathrm{kg}-100 \mathrm{rpm}$ & \\
Power output & $166 \pm 37 \mathrm{~W} \quad 115 \pm 13 \mathrm{~W}$ \\
Difference & $50 \pm 30 \mathrm{~W}(43 \pm 24 \%)$ \\
$\mathrm{p}$ & $<0.01^{*}$ \\
Cohen's $d$ & 1.35 (large) \\
$\mathrm{TE}$ & $21 \mathrm{~W}(17 \%)$ \\
$\mathrm{ICC}$ & 0.41 (poor) \\
\hline
\end{tabular}

\begin{tabular}{lc}
\hline $2.5 \mathrm{~W} / \mathrm{kg}-100 \mathrm{rpm}$ & \\
Power output & $223 \pm 33 \mathrm{~W} \quad 182 \pm 9 \mathrm{~W}$ \\
Difference & $41 \pm 30 \mathrm{~W}(23 \pm 17 \%)$ \\
$\mathrm{p}$ & $0.01^{*}$ \\
Cohen's $d$ & 1.29 (large) \\
$\mathrm{TE}$ & $22 \mathrm{~W}(12 \%)$ \\
$\mathrm{ICC}$ & 0.36 (poor) \\
\hline $3.5 \mathrm{~W} / \mathrm{kg}-100 \mathrm{rpm}$ & $270 \pm 34 \mathrm{~W} \quad 251 \pm 15 \mathrm{~W}$ \\
Power output & $19 \pm 34 \mathrm{~W}(12 \pm 13 \%)$ \\
Difference & 0.28 \\
$\mathrm{p}$ & 0.78 (moderate) \\
Cohen's $d$ & $24 \mathrm{~W}(9 \%)$ \\
TE & 0.34 (poor) \\
ICC & \\
\hline
\end{tabular}

* significant difference between the pedals and the Lode ergometer

\section{Discussion}

The present study assessed within- and betweensession reliability of power output and pedalling technique and compared power output measured by a customized system with a cycle ergometer. The agreement in power output measured by the pedals in relation to the cycle ergometer was also analysed. The results indicated that measures from the customized pedal force-motion tracking system were generally reliable within sessions, but the reliability reduced in comparison with a second session. The comparison of power output with the cycle ergometer indicated that agreement was reduced, and differences were larger than those observed in prior studies [7, 12]. These findings are new as they provide evidence that customized sys- 
tems to measure power output and pedalling technique should be used carefully. The main consideration for reduced reliability is the combination of different sensors with varying procedures for users. For the comparison performed in this study between pedals and the cycle ergometer, the absence of measurements of pedal and crank angles by using built-in encoders may have been an important component of differences. Of particular attention, portable technology, such as the motion tracking system applied in this study, should be used wisely as these systems tend to be sensitive to environmental (e.g. magnetic field) and user interference. Given that Van Praagh et al. [30] suggested that the technical error for power output measures from exercise ergometers should be less than $5 \%$, the system employed in this study was considered only reliable for comparison of data within a given session.

\section{Within-session reliability}

Differences within a given session were expected to be lower than those between different sessions because of different elements. The first element involves the variability of cyclists in reproducing their pedalling technique, which has been shown to vary by $5-14 \%$ for pedal force measures [31]. However, the proportion of overall variability from movement patterns and from errors in equipment is unclear. Trained cyclists have been shown to vary their IE by $7.7-12.4 \%$ within the same session [32], which is related to the potential existence of 4 synergies that control muscle activation during cycling [33]. Therefore, differences between trials observed in the present study were lower than prior findings, which suggests that our cyclists were consistent in their pedalling pattern and that the customized pedal force-motion tracking system was capable of detecting differences of $>4 \%$ in IE within the same session.

For power output, differences were larger than the variability observed in elite cyclists (i.e. $2 \%$ ) when performing constant-load testing [34]. The larger variability in our results may be due to our cyclists being competitive, which could reduce their consistency in comparison with elite cyclists. In addition, the true variability of the cycle ergometer in controlling power output was uncertain. When using the constant wattage more, the ergometer modulated the wheel resistance whenever pedalling cadence was changed. From observations during data collection and other testing, we found that the ergometer seemed to lag 1-2 s before changing the resistance when cadence deviated from targeted values. Further investigation is required to determine the threshold used by the ergometer to control wheel resistance, which would help understand the expected variability in moment of inertia when the angular velocity changes.

\section{Between-session reliability}

Differences in power output and IE increased when compared with the second session. Pedal forces and IE were expected to vary by $5-14 \%$ between sessions because of similar elements as in the within-session analysis (i.e. variability in technique) [31]. Unfortunately, no study has assessed trained cyclists for such a comparison. This is important as coaches and practitioners more often use motion analysis technology to assess changes in pedalling technique from training, or to determine the effectiveness of bike fitting in changing pedalling patterns.

As most of the clinical-based commercial systems now rely on portable/wearable sensors, our study provides information for the assessment of reliability of such systems in clinical practice. Unfortunately, for power output, most trials have shown between-session variability larger than suggested previously [30], which limits the use of these systems to detect large changes. For performance monitoring, the customized pedal force-motion tracking system would not be able to detect improvements from interventions (i.e. between sessions) in power output lower than $20 \%$ for some trials. For pedalling technique, changes less than $4 \%$ would not be detectable, which is lower than findings from prior studies employing technique-oriented interventions $[35,36]$.

A potential source of difference, particularly for wearable technology, involves the position of sensors on the body. The motion tracking system used in this study provided generic instructions on how sensors should be positioned in relation to anatomical landmarks, which in our view increased the likelihood of differences in measurements whenever the sensors were repositioned. A prior study observed that this could be the case for vertical jumps [37], which conflicted with another study, looking at walking gait [38]. Further research is required to assess the extent of the variability in other measures, such as joint angles, moments, and forces, and to determine if the use of a baseline trial for data normalization could reduce the between-participant variability between sessions. This normalization would allow comparisons in relation to a given combination of power output and pedalling cadence, similar to analysis of electromyographic data in cycling [39]. 


\section{Cycle ergometer comparison}

The results from this study showed that power output measured by the customized pedal force-motion tracking system was substantially different from the pre-set power output from the cycle ergometer. Although the Lode Excalibur ergometer has been widely used for measurements of power output [7, 18] and torque [40], we were unable to find studies on the validity of these measures taken from a calibration rig, which is the gold standard in assessing accuracy of power meters [41]. Therefore, a proportion of the differences between pedals and the cycle ergometer could be due to the previously referred instantaneous control of the wheel resistance when cadence fluctuated. This could have inflated the differences between systems to an unknown extent.

Along this line of reasoning, a portion of the differences could have relied on the methods used for deriving foot-pedal angles, which are critical for calculating crank torque and power. We extracted predicted body landmarks from the motion tracking system to determine the inclination of the foot-pedal in the global coordinate system throughout the crank cycle. These predicted landmarks have not been compared with a camera-based system for accuracy. Therefore, variability in predicting the foot-pedal position in the software modelling could have influenced our precision in determining the magnitude of force transferred from the pedals to the cranks, which largely affects crank torque. The fact that the angular velocity was derived from pedalling cadence should have had a small effect on force transmission. Although the pedal force system has built-in pedal encoders, data from these devices were not reliable when the crank encoder was not applied. This limitation requires the use of an external sensor for foot-pedal-crank motion, which can be prone to errors, as shown by our data.

Another possible factor in calculations of power output was related to the magnetic field from the cycle ergometer. The foot sensors detected some magnetic interference, which affected the biomechanical model. The updated version of the motion tracking system has shown improved results in terms of magnetic interference for over-ground walking gait [42] but further studies are needed to assess its use with other devices that could produce magnetic interference (e.g. exercise equipment, ergometers).

\section{Limitations}

Data from this study were limited to a certain extent. The protocol was designed to cover a reasonable range of power outputs and cadences but we were unable to perform sprints. In addition, further studies should assess if changes in body position on the bicycle (e.g. standing) would influence measurements of power outputs within and between sessions as a result of an increase in degrees of freedom. We were also unable to use a validated power meter (e.g. SRM) to ascertain true differences in power output from the customized pedal force-motion tracking system. It would be beneficial to adapt the customized system for outdoor use (e.g. tracks) as this would provide real-time feedback for cyclists and coaches during training sessions.

\section{Conclusions}

A customized system to measure pedal forces that employed different sensors was reliable within a given session for measurements of pedalling technique and power output. However, variability in data increased in a second session, with differences in power output in relation to the cycle ergometer limiting the use of this system for intervention studies whenever motion tracking sensors would have to be repositioned. Significant differences in power output between the pedals and the cycle ergometer also preclude the use of the pedals to monitor power output during training interventions.

\section{Funding}

The project was funded by the Sports Kinesiology and Injury Prevention research group (SKIP) from the Sports Performance Research Institute New Zealand, Auckland University of Technology.

\section{Acknowledgments}

We would like to thank Tasman Nankervis for assistance in data collection. We would also like to thank all cyclists who volunteered for this study.

\section{Disclosure statement}

No author has any financial interest or received any financial benefit from this research.

\section{Conflict of interest}

The authors state no conflict of interest.

\section{References}

1. Etxebarria N, D’Auria S, Anson JM, Pyne DB, Ferguson RA. Variability in power output during cycling in international Olympic-distance triathlon. Int J Sports Physiol Perform. 2014;9(4):732-734; doi: 10.1123/ ijspp.2013-0303.

2. Vogt S, Heinrich L, Schumacher YO, Blum A, Roecker K, Dickhuth $\mathrm{HH}$, et al. Power output during stage racing 
in professional road cycling. Med Sci Sports Exerc. 2006;38(1):147-151; doi: 10.1249/01.mss.0000183196. $63081.6 \mathrm{a}$

3. Hull ML, Davis RR. Measurement of pedal loading in bicycling: I. Instrumentation. J Biomech. 1981;14(12): 843-856; doi: 10.1016/0021-9290(81)90012-9.

4. Dorel S, Couturier A, Lacour JR, Vandewalle H, Hautier C, Hug F. Force-velocity relationship in cycling revisited: benefit of two-dimensional pedal forces analysis. Med Sci Sports Exerc. 2010;42(6):1174-1183; doi: 10.1249/MSS.0b013e3181c91f35.

5. Bini RR, Daly L, Kingsley M. Muscle force adaptation to changes in upper body position during seated sprint cycling. J Sports Sci. 2019;37(19):2270-2278; doi: 10.1080/02640414.2019.1627983.

6. Hoes MJAJM, Binkhorst RA, Smeekes-Kuyl AEMC, Vissers ACA. Measurement of forces exerted on pedal and crank during work on a bicycle ergometer at different loads. Int Z Angew Physiol Einschl Arbeitsphysiol. 1968;26(1):33-42; doi: 10.1007/BF00696088.

7. Pallarés JG, Lillo-Bevia JR. Validity and reliability of the PowerTap P1 pedals power meter. J Sports Sci Med. 2018;17(2):305-311.

8. Nimmerichter A, Schnitzer L, Prinz B, Simon D, Wirth K. Validity and reliability of the Garmin Vector power meter in laboratory and field cycling. Int $\mathrm{J}$ Sports Med. 2017;38(6):439-446; doi: 10.1055/s-0043101909.

9. Wright J, Walker T, Burnet S, Jobson SA. The reliability and validity of the PowerTap P1 power pedals before and after 100 hours of use. Int J Sports Physiol Perform. 2019;14(6):855-858; doi: 10.1123/ijspp.2018-0563.

10. Sparks SA, Dove B, Bridge CA, Midgley AW, McNaughton LR. Validity and reliability of the Look Keo power pedal system for measuring power output during incremental and repeated sprint cycling. Int J Sports Physiol Perform. 2015;10(1):39-45; doi: 10.1123/ijspp.2013-0317.

11. Bouillod A, Pinot J, Soto-Romero G, Bertucci W, Grappe F. Validity, sensitivity, reproducibility, and robustness of the PowerTap, Stages, and Garmin vector power meters in comparison with the SRM device. Int J Sports Physiol Perform. 2016;12(8):1023-1030; doi: 10.1123/ ijspp.2016-0436.

12. Novak AR, Dascombe BJ. Agreement of power measures between Garmin Vector and SRM cycle power meters. Meas Phys Educ Exerc Sci. 2016;20(3):167-172; doi: 10.1080/1091367X.2016.1191496.

13. Bini RR, Hume PA, Croft J, Kilding AE. Pedal force effectiveness in cycling: a review of constraints and training effects. J Sci Cycling. 2013;2(1):11-24; doi: 10.28985/jsc.v2i1.32.

14. Korff T, Romer LM, Mayhew I, Martin JC. Effect of pedaling technique on mechanical effectiveness and efficiency in cyclists. Med Sci Sports Exerc. 2007;39(6): 991-995; doi: 10.1249/mss.0b013e318043a235.

15. Zameziati K, Mornieux G, Rouffet D, Belli A. Relationship between the increase of effectiveness indexes and the increase of muscular efficiency with cycling power. Eur J Appl Physiol. 2006;96(3):274-281; doi: 10.1007/s00421-005-0077-5.

16. LaFortune MA, Cavanagh PR. Effectiveness and efficiency during bicycle riding. In: Matsui HK, Kobayashi K (eds.), International Series on Biomechanics. Champaign: Human Kinetics; 1983; 928-936.

17. Patterson RP, Moreno MI. Bicycle pedalling forces as a function of pedalling rate and power output. Med Sci Sports Exerc. 1990;22(4):512-516.

18. Granier C, Hausswirth C, Dorel S, Yann LM. Validity and reliability of the Stages cycling power meter. J Strength Cond Res. 2017; Epub ahead of print; doi: 10.1519/jsc.0000000000002189.

19. Herbert P, Sculthorpe N, Baker JS, Grace FM. Validation of a six second cycle test for the determination of peak power output. Res Sports Med. 2015;23(2)115125; doi: 10.1080/15438627.2015.1005294.

20. Bernard J, Decatoire A, Lacouture P. Comparison of two pedaling sensors, ICrankset and SRM, against a standard reference sensor. In: Colloud F, Domalain M, Monnet T (eds.), $33^{\text {rd }}$ International Conference on Biomechanics in Sports, Poitiers, France, June 29-July 3, 2015. 2015; 525-528.

21. Bini RR, Hume PA, Kilding AE. Saddle height effects on pedal forces, joint mechanical work and kinematics of cyclists and triathletes. Eur J Sport Sci. 2014;14(1):4452; doi: 10.1080/17461391.2012.725105.

22. Robert-Lachaine X, Mecheri H, Larue C, Plamondon A. Validation of inertial measurement units with an optoelectronic system for whole-body motion analysis. Med Biol Eng Comput. 2017;55(4):609-619; doi: 10.1007/s11517-016-1537-2.

23. Al-Amri M, Nicholas K, Button K, Sparkes V, Sheeran L, Davies JL. Inertial measurement units for clinical movement analysis: reliability and concurrent validity. Sensors. 2018;18(3):719; doi: 10.3390/s18030719.

24. Blair S, Duthie G, Robertson S, Hopkins W, Ball K. Concurrent validation of an inertial measurement system to quantify kicking biomechanics in four football codes. J Biomech. 2018;73:24-32; doi: 10.1016/j.jbiomech.2018.03.031.

25. Bini RR, Hume PA. Effects of workload and pedalling cadence on knee forces in competitive cyclists. Sports Biomech. 2013;12(2):93-107; doi: 10.1080/14763141. 2012.731428.

26. Bini RR, Senger D, Lanferdini FJ, Lopes AL. Joint kinematics assessment during cycling incremental test to exhaustion. Isokinet Exerc Sci. 2012;20(2):99-105; doi: 10.3233/IES-2012-0447.

27. Hopkins WG. Measures of reliability in sports medicine and science. Sports Med. 2000;30(1):1-15; doi: 10.2165/ 00007256-200030010-00001.

28. Koo TK, Li MY. A guideline of selecting and reporting intraclass correlation coefficients for reliability research. J Chiropr Med. 2016;15(2):155-163; doi: 10.1016/j.jcm. 2016.02.012. 


\section{HUMAN MOVEMENT}

R. Bini, P. Hume, Reliability of a pedal force system

29. Cohen J. Statistical power analysis for the behavioral sciences. New York: Lawrence Erlbaum Associates; 1988.

30. Van Praagh E, Bedu M, Roddier P, Coudert J. A simple calibration method for mechanically braked cycle ergometers. Int J Sports Med. 1992;13(1):27-30; doi: 10.1055/s-2007-1021229.

31. Bini RR, Hume PA. Between-day reliability of pedal forces for cyclists during an incremental cycling test to exhaustion. Isokinet Exerc Sci. 2013;21(3):203-209; doi: 10.3233/ies-130510.

32. Hug F, Drouet JM, Champoux Y, Couturier A, Dorel S. Interindividual variability of electromyographic patterns and pedal force profiles in trained cyclists. Eur J Appl Physiol. 2008;104(4):667-678; doi: 10.1007/ s00421-008-0810-y.

33. De Marchis C, Schmid M, Bibbo D, Bernabucci I, Conforto $\mathrm{S}$. Inter-individual variability of forces and modular muscle coordination in cycling: a study on untrained subjects. Hum Mov Sci. 2013;32(6):1480-1494; doi: 10.1016/j.humov.2013.07.018.

34. Paton CD, Hopkins WG. Tests of cycling performance. Sports Med. 2001;31(7):489-496; doi: 10.2165/0000 7256-200131070-00004.

35. Broker JP, Gregor RJ, Schmidt RA. Extrinsic feedback and the learning of kinetic patterns in cycling. J Appl Biomech. 1993;9(2):111-123; doi: 10.1123/jab.9.2.111.

36. Bini RR, Jacques TC, Carpes FP, Vaz MA. Effectiveness of pedalling retraining in reducing bilateral pedal force asymmetries. J Sports Sci. 2017;35(14):13361341; doi: 10.1080/02640414.2016.1215505.

37. Bini RR, Jayalath L, Wundersitz D, de Noronha M. Variability in vertical jump height and lower limb kinematics between days. In: $36^{\text {th }}$ Conference of the International Society of Biomechanics in Sports, Auckland, New Zealand, September 10-14, 2018. 2018;988-991.

38. Cloete T, Scheffer C. Repeatability of an off-the-shelf, full body inertial motion capture system during clinical gait analysis. Conf Proc IEEE Eng Med Biol Soc. 2010; 2010:5125-5128; doi: 10.1109/IEMBS.2010.5626196.

39. Bini RR, Jacques TC, Lanferdini FJ, Vaz MA. Comparison of kinetics, kinematics, and electromyography during single-leg assisted and unassisted cycling. J Strength Cond Res. 2015;29(6):1534-1541; doi: 10.1519/jsc. 0000000000000905.

40. García-López J, Díez-Leal S, Ogueta-Alday A, Larrazabal J, Rodríguez-Marroyo JA. Differences in pedalling technique between road cyclists of different competitive levels. J Sports Sci. 2016;34(17):1619-1626; doi: 10.1080/02640414.2015.1127987.

41. Abbiss CR, Quod MJ, Levin G, Martin DT, Laursen PB. Accuracy of the Velotron ergometer and SRM power meter. Int J Sports Med. 2009;30(2):107-112; doi: 10.1055/s-0028-1103285.

42. Marreiros S, Schepers M, Bellusci G, de Zee M, Andersen MS. Comparing performance of two methods to process inertial data in gait analysis. In: XXVI Congress of the International Society of Biomechanics, Brisbane, Australia, 23 Jul 2017-27 Jul 2017. 2017. 